\title{
Towards a Global Culture of Heritage Interpretation? Evidence from Indonesia and Tanzania
}

\author{
NOEL B. SALAZAR
}

\begin{abstract}
Natural and cultural heritage destinations worldwide are adapting themselves to the homogenizing culture of tourism and at the same time trying to maintain, or even increase, their local distinctiveness. While local and national tourism authorities and travel agencies package and sell so-called 'authentic' natural landscapes or 'traditional' cultures, what counts as heritage and the way in which it is interpreted are increasingly defined on a global scale (e.g., UNESCO's World Heritage policies). By way of a comparative case study, this paper examines how local tour guides in Yogyakarta, Indonesia (cultural heritage tourism destination), and Arusha, Tanzania (natural heritage tourism destination), learn to tell their foreign guests seducing tourism tales. Combining an in-depth ethnography of the local tourism industry with a discourse-centred analysis of guiding narratives, the author explores the relationship between global tourism discourses and local tour guiding in both destinations. The focus is on how guides, through their interpretations of local heritage, act as key actors in mediating the tension between ongoing processes of globalization and local differentiation. Paradoxically, guides seem to rely on fashionable global tourism tales to interpret and sell their culture and heritage as authentically 'local'. This is partly because tourists appear to appreciate interpretations that combine narratives about the particularities of a destination with well-known tourism imaginaries that are circulating globally. However, this does not mean that guides merely reproduce normative templates. In the interaction with tourists, they become themselves creative producers of tourism rhetoric.
\end{abstract}

Keywords: tour guides; heritage interpretation; discourse; anthropology; ethnography; Indonesia; Tanzania.

\section{Introduction}

Knowledge of the world is based largely on the discursive representations people make of it. The notion of 'discourse' refers in this context to language as a form of practice that is deeply embedded in the social conditions of production and consumption and the cultural processes of meaning-making (Fairclough 2003). Discourses, as tools of knowledge and power, not only represent the world as it is (or rather as it is seen to be), they are also projective 'imaginaries' (Gaonkar and Lee 2002), representing possible worlds that are different from the actual world, and often tied in to projects to change it in particular directions. In tourism, discursive imaginaries travel throughout the selfperpetuating 'touristic cycle' (Bruner 2005), by people who have very different stakes in tourism (e.g., marketers, service providers, government agencies, the media, and tourists). These widely circulating discourses are instrumental in the creation of a global 'culture of tourism' (Rojek and Urry 1997).

Seducing discourses are so predominant that without them there probably would be little tourism if at all (Dann 1996). Tourism imaginaries, however, have to be situated within circuits of wider cultural discourses (Morgan and Pritchard 1998). Indeed, critical scholarship has revealed how touristified representations are created and mediated through broader cultural and ideological structures (Hannam and Knox 2005; Mowforth and Munt 2003; Selwyn 1996; Urry 2002). All narratives, appearing at different times (pre-tour, on-tour, and post-tour) and places (at home and away), and in various modalities (oral, written, pictorial, symbolic, or graphic), can be traced back to the same 'master narrative' (Bruner 2005). Not surprisingly, the currently dominant language - e.g., marketing products as eco-tourism and nostalgia tourism - is heavily influenced by mythologized (often Western) visions of 'Otherness' from popular culture, (travel) literature, and academic writings in disciplines like anthropology, archaeology, art, and history (Clifford 1997; Pratt 1992; Said 1994; Torgovnick 1990).

In order to understand how global tourism and its foundational imaginaries perpetuate themselves, theoretical frameworks are needed that allow a comprehensive study of their inner dynamics that transcend the unproductive binary opposition between the 'economic global' and the 'cultural local'. One such holistic conceptualization is the 'circuit of culture' model, which encompasses the production, circulation, and consumption of culture (Du Gay et al. 1997).

NOEL B. SALAZAR is Ph.D. Candidate in the Department of Anthropology, University of Pennsylvania, University Museum Rm. 323,3260 South Street, Philadelphia PA 19104, USA. e-mail: nsalazar@sas.upenn.edu 
This cultural studies theory has its roots in Marxist conceptions of circuits of capital(ism), and the reconstruction of this by Johnson (1986). The circuit depicts the cultural process as a complex and interdependent set of distinct but not discrete moments. This holistic model helps us understand how culture deploys power to shape identities and subjectivities within a circuit of practices that range from the production and distribution of goods and representation to an ever-growing emphasis on regulation and consumption. The study of individual moments at which meaning is constructed only gives us a partial view of how the meanings associated with a particular cultural product are produced, negotiated, and contested. The circuit of culture idea moves away from one-way processes to viewing globally circulating products and processes in a more integrated way as circulation and dissemination.

Several scholars have applied the circuit of culture concept to tourism (Bruner 2005; Dann 1996: 136-169; Jenkins 2003; Norton 1996; Said 1994: 92-95). According to Ateljevic, circuits of tourism are 'a dynamic interconnected whole, where players and stakeholders may (re)align themselves with any other player or stakeholder as need, desire or opportunity allows' (2000: 382). Norton (1996) modified the 'circuit of culture' model for the specificities of tourism, paying attention to the circulation of tourism culture by the industry as well as tourists, suggesting tourism as an arena for discourse construction and manipulation (see Figure 1).

A related theoretical approach that also stresses the dialectics of production and consumption uses the metaphor of 'tourism as performance' - a mutually negotiated relationship between producers and consumers. This kind of theorizing is an attempt to move beyond the passive gaze of the visual and to explore the embodiment of the acts of

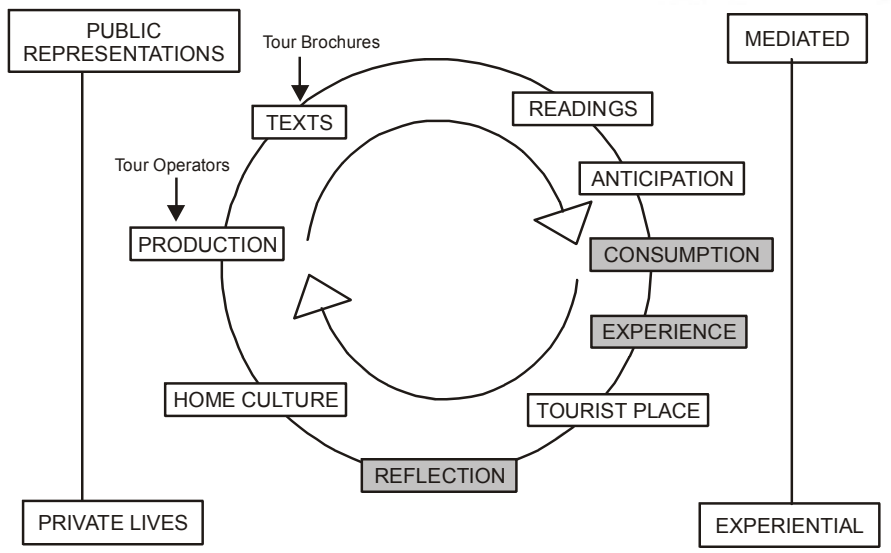

Figure 1. The 'Circuit of Culture Model' in Tourism

Source: Norton 1996: 360 production and consumption (e.g., Bærenholdt et al. 2004; Coleman and Crang 2002). Such approaches allow scholars to study how the existing power relations and inequalities that characterize the circuit of tourism are maintained, reproduced, and reinforced as well as they are challenged, contested, and transformed (Edensor 2001).

While there is ample scholarship on the production and consumption of tourism discourses (Dann 1996; Morgan et al. 2002; Selwyn 1996), much less attention has been given to their actual distribution within the circuit of tourism. The replication and dissemination of discourse is a multifaceted process (Silverstein and Urban 1996) and globalization the process of growing worldwide interconnectedness and interdependency - has added extra layers of complexity to the way tourism imaginaries circulate. Because the logic of the market prescribes diversification and the creation of multiple consumer identities, marketing contains a wide number of registers, each one of them addressing a certain type of potential client with specific interests (Morgan et al. 2002). These various discourses circulate globally through an intricate system of artefacts and communication devices: brochures, (guide) books, novels, newspapers and magazines, television programmes and films, museums, popular culture, textbooks, student exchange programmes, conferences, and the Internet. As discourses are being '(re)entextualized' (reproduced with an altered form) or '(re)contextualized' (reproduced identically), innumerable factors intervene, and the copy is very often distinct from the original. Because there is frequently an asymmetrical power relationship between the originator(s) and the copier(s), the original discourse is not only copied but is reacted or responded to. However, the more discourse is overtly coded as non-personal, and the less it is linked to a present context and circumstances, the more likely will the copier be inclined to replicate it (Urban 2001). This applies remarkably well to tourism.

Tourism imaginaries are powerful in the sense that they turn places and peoples into easily consumable attractions, providing simplified and historically fixed versions of local heritage. Since the natural and cultural heritage of a destination is what many international tourists are seeking to experience, the (re)production of their representations becomes a contested arena of conflicting interests. Heritage interpretation can be used, for example, as a political instrument for forming or transforming national identities, and justifying political power. Destinations worldwide are adapting themselves to the homogenizing corporate culture of tourism at the same time as trying to commoditize their local distinctiveness. While they promote and sell the packaged experience of so-called 'authentic' natural landscapes or 'traditional' cultures, what counts as heritage

\section{Copyright - 2007 : Tourism Recreation Research Subscribe Online at www.trrworld.org}


and the way it is interpreted are increasingly defined on a global scale (e.g., UNESCO's World Heritage policies). The more tourism grows, the more its selective representations of life tend to become the codified and authorized versions of local culture and knowledge and the ways tourists should experience and interpret it. Many local people have little (economic) choice but to accept and to adapt to the 'tourismified' scripted identities and cultural views created for them. At the same time, this global overhaul stimulates the resurgence of local identities and competing counterdiscourses of natural and cultural heritage (Hall and Tucker 2004; Porter and Salazar 2005; Salazar and Porter 2004).

Local service providers are not without stake in the (re)creation and promotion of fashionable tourism tales. Tour guides, for example, are creative (re)producers of profitable myth-making narratives. They tailor local - and localized - products (interpretations of local natural and cultural heritage) to changing global audiences (tourists coming from various parts of the world and with different interests). Guides are often the only 'local people' with whom tourists interact for a considerable amount of time during their trip. They are, therefore, entrusted with the public relations mission to 'encapsulate the essence of place' (Pond 1993: vii) and to be a window onto a site, region, or even country or continent. While a number of guides take pride in representing and explaining local heritage and culture, others are more business-oriented and merely interested in selling - images, knowledge, contacts, souvenirs, access, authenticity, ideology, and sometimes even themselves (Bras 2000).

As originally defined by Tilden (1967), interpretation is an educational activity aimed at revealing meanings and relationships to people about the places they visit and the things they see and do there. In the context of global tourism, it is important to understand who defines and controls the content and form of interpretative practices. Through a comparative case study of a small but remarkable transnational network of local tour guides in Yogyakarta, Indonesia, and Arusha, Tanzania, this paper explores the multiple ways in which guides learn to internalize and mirror the normative global templates of interpretation. In order to understand how they (re)produce and contest globalized tourism imaginaries, special attention is paid to the meta-communicative dimension of their narratives and practices.

\section{Ethnographic Scene and Methodology}

The research for this paper was undertaken in Yogyakarta, Indonesia during summer 2003, and Arusha, Tanzania during summer 2004. These two sites were selected because both are home to a group of local tour guides who are linked to a loosely organized transnational tourism network, with other members in Senegal, Mali, Nepal, Honduras, Nicaragua, Argentina, Belgium, and Spain. The guides in Yogyakarta and Arusha joined the network in 1995 and 2000 respectively. The Indonesian and Tanzanian guides are the only non-European members of the network to have met in person when delegations from both countries were invited by the European section of the network for a one-month visit to Europe in the spring of 2002. During this period, the guides underwent an intense two-week experience as international tourists - a kind of role reversal exercise - and participated in an interactive course on interpretation and intercultural communication. This unique network constellation gave the author numerous opportunities to study the complex links between global tourism imaginaries and local tour guiding (Salazar 2005, 2006).

Yogyakarta is the name of both a province on the island of Java and its capital, a city with a population reaching half a million. The region has been participating in international tourism for almost 30 years. Since the early stages of tourism, it was promoted by the Indonesian government as 'the cultural heart of Java' (or even Indonesia or Asia), and an ideal cultural heritage destination for both domestic and international markets. The most important attractions include the eighth century Buddhist stupa of Borobudur and the tenth century Hindu temple complex of Prambanan (both listed as UNESCO World Heritage sites). The city, with its Kraton - the eighteenth-century walled palace where the Sultan resides - cherishes its Javanese roots, attracting a large number of painters, dancers, and writers. Yogyakarta is famous for crafts such as batik (textile design), silverware, pottery, clothing, woodcarving, and wayang (puppets). Recently, 'Jogja' was introduced as a brand name to market the region since the letter ' $Y$ ' was believed to be a more difficult alphabetical start for most international audiences. This brand name also appears in 'Jogja, never ending Asia', the catchphrase currently used by the local authorities to attract investors, traders, and tourists to the region.

Arusha, a city with an estimated population of 300,000 people, is situated in northern Tanzania, on the eastern edge of the Great Rift Valley. It is often called the 'safari capital', because it is the gateway to Lake Manyara, Tarangire, Arusha, Serengeti, and Mount Kilimanjaro national parks, and the Ngorongoro Conservation Area (the latter three are UNESCO World Heritage sites). International tourism was first established under German and British colonial rule, catering to the needs of Westerners coming to observe and hunt 'exotic' animals. Hunting, however, has been replaced largely

\section{Copyright - 2007 : Tourism Recreation Research Subscribe Online at www.trrworld.org}


by photographic safaris. Many of the region's wildlife landscapes, especially the wide plains of the Serengeti, have become popular icons for Africa as a whole and have provided nature documentaries and Hollywood entertainment with their perfect romantic and nostalgic vision of an unexplored and time-frozen 'wild Eden'. Not surprisingly, Tanzania capitalizes on this well-known iconology. The country's latest promotional campaign for the global market, 'Tanzania - Authentic Africa', powerfully encapsulates it all. The city of Arusha also strategically markets the fact that, being situated halfway between Cape Town (South Africa) and Cairo (Egypt), it is 'the centre of Africa'.

The methodology used for this research involves a hybrid ethnographic and discourse-centred approach, involving two visits lasting ten weeks. As the research in both sites took place during the peak of the tourism season, there were many opportunities to engage in participant observation and interviewing. Throughout his stay, the author observed the daily activities of the transnationally networked guides, accompanying them on tours. Each guide also agreed to have two semi-structured in-depth interviews and multiple shorter, open-ended interviews. Additional short semi-structured interviews were conducted with other service providers, key players in the local tourism sector, and tourists. All primary qualitative data - field notes, interviews, and audio recordings of the guiding narratives were coded and interpreted with the help of Atlas.ti, a popular software package for visual qualitative data analysis. In what follows, a brief overview is given of some of the striking features of the observed guiding narratives and practices. Due to space constraints, the lengthy ethnographic examples illustrating the theoretical points are reduced to a minimum.

\section{The Art of 'Seducation': Theory and Practice}

Neither the Indonesian nor the Tanzanian guides under study received much formal training in interpretation. In Yogyakarta, all the guides have previous working experience in the tourism industry, usually as service providers in restaurants or hotels. They built up their guiding skills by observing the practices of older guides and specializing in one or two particular tours. In Arusha, the situation is slightly different. In Tanzania, there is currently no official policy or programme implemented to train, certify, and license guides. However, safari tourism usually involves tours lasting a couple of days and driver-guides cannot survive without having had some form of preparation. All guides studied received at least a general training at a private tour guide school (partly sponsored by the transnational network of which they are part).
The guides in both destinations have had the opportunity to experience firsthand how it feels like to be an international tourist. As part of their ongoing training, they were offered a kind of European internship. In the spring of 2002, they underwent an intense two-week experience as tourists. The trip was organized by the European part of their network, with the aim of giving the guides more insight into European culture, in order to understand the behaviour of their European clients. The whole group also participated in a two-week interactive course on interpretation and intercultural communication. Mastering all this new knowledge was a huge task, especially given the fact that most guides lack a formal framework to which they can relate the information. The lack of vulgarization and adaptation of materials to the local context makes it often difficult to appropriate foreign knowledge. Besides, what is learned in a classroom setting is one thing; the way in which the taught scripts play out while guiding is another. Building on their initial meeting in Europe, the guides on the two continents stay in touch with one another and often rely on their unique global connectedness and experience when interacting with tourists.

\section{The Rhetoric of Interpretation}

Apart from building up professional skills, guides need to understand the currency of their interpretative narratives in a global market that is highly unstable and influenced by continuous changes in consumer cultures. This requires them to endlessly reinvent and market their services as well as to vary and customize them. Guides have to learn which objects of attention to select, what details to elaborate on, and which jokes to tell. In other words, they need to master the currently popular global tourism imaginaries and their discourses. Guides have to give evidence of mastering a vast amount of knowledge and an accompanying expert register (Moscardo 1998). As such, guiding can be seen as a public display of competence, both of knowledge and of language proficiency. However, guiding stories are distinct from other tourism language genres (Dann 1996). Guiding consists of rather complex speech chains whereby long stretches of interpretative monologue are interspersed with parts of intense interaction and dialogue of various kinds. What actually happens during the interaction with tourists is very nuanced and open-ended. Tourists might ask questions, and the guides themselves often engage in culturally sensitive small talk. The latter is typically used to fill the gap between stretches of explanatory guiding narrative. During the interaction, expectations and preconceived patterns can be creatively manipulated.

In the context of international tourism, the language of contact between local guides and tourists is often a kind of

\section{Copyright - 2007 : Tourism Recreation Research Subscribe Online at www.trrworld.org}


international English. In some cases, guides will downplay their language proficiency, especially when they notice that tourists have problems speaking and/or understanding English. Most tours in Yogyakarta and Arusha are multilingual experiences. Among each other, tourists speak their native tongue (if the group shares a common language) or English (if the group is mixed or has English as a native tongue). The tourists receive explanations and instructions from the guide in an Indonesian or Tanzanian form of international English, with occasionally the use of an Indonesian or Swahili term, typically to indicate a certain local craft, food, plant, or animal. Paradoxically, the simplified use of national languages (often different from local ones) is a powerful tool used to manipulate the tourist experience and make it feel more 'authentically local'. For many tourists, for example, Swahili is not the language of a particular country or people, but a symbol of Africa as a whole, of the safari and its related images of romance, adventure, and fun under the African sun (Bruner 2005). The use of simplified languages invites tourists to reproduce some of the phrases from their travel phrasebooks. When interacting with the autochthonous population, however, the linguistic situation becomes more complex, with the local Indonesian guides switching to Javanese and some Tanzanian guides talking in Maa (language of the Maasai) or other local languages. Given the language barrier, the direct contact between tourists and locals is often minimal and the tourists have to rely on the guide as mediator and translator.

The whole tour experience is professionally framed and manipulated. The guarantee that what is marketed and sold will be seen and experienced becomes a self-fulfilling prophecy, directing expectations, influencing perceptions, and thereby providing a preconceived landscape for the tourist to discover. Tour guides play an important role in reinforcing these predetermined images. They have to make sure that people experience exactly the kind of things that they expect and which were sold to them by tour operators or travel agencies (what Dann (1996) calls the 'tourism tautology'). Even if they would like to, guides often cannot go much beyond a commoditized, reductionist, touristified representation of local life because that is precisely what the tourists came to hear or see. They will try everything they can to make their clients feel 'at home', relying on discourses tourists heard before (throughout the tourism cycle). They do this by strategically using the normative global set of genres and strategies that they have skilfully appropriated (at school or through practice). The guides' ever-changing (re)presentation of the local culture is always fine-tuned to the different tastes of specific groups or socio-cultural backgrounds. This requires interpreting both the linguistic and non-linguistic cues provided by tourists and carefully balancing the interest of the tour group against the interest of individuals and the guide's personal interests. Here again, international experience comes in handy. Paradoxically, it is their global knowledge that helps guides to present the reality around them to tourists as a distinctive, 'mythologized' version of 'the local', and not as is currently being lived and internalized by most autochthones.

While touring, guides give detailed explanations about the local, cultural and natural heritage. By highlighting certain elements of the places visited over others, they take control, distracting tourists from things that they want to keep hidden (e.g., people living in misery or environmental degradation). In their narratives, they tend to focus on aspects that are unlike the tourists' own culture and traditions or elements that are strikingly similar. Consequently, the discourse slightly changes when dealing with tourists from different cultural backgrounds. Guides also subtly adapt the depth of information provided to the estimated average intellectual level of the group. Using a flexible expert register, they try to establish a genuine connection between their clients and 'the local' (Weiler and Ham 2001). Again, they are only able to do this successfully because they are somehow familiar with the home culture of many tourists. For the guides, it is not always a matter of getting things right, but of impressing, pleasing, and seducing tourists. Typical is the dual role of a heritage interpreter as both educator and entertainer (Uzzell 1989). Of course, the tourist's dependence on the guide's knowledge and interpretation is balanced by the guide's dependence on the tourist's money. After all, tour guiding is about providing clients a (paid for) service. However, this asymmetrical alignment, typical for service encounters, is often blurred or temporarily interrupted.

\section{Shifting Positionalities}

Guides rely on dualisms or binary 'us' versus 'them' oppositions to interactionally position themselves vis-à-vis tourists and local people. Two different logics are at work here simultaneously: a logic of difference that creates differences and divisions, and a logic of equivalence that subverts existing differences and divisions. As marketing prescribes, guides behave and perform as the 'locals' that many tourists expect and perceive them to be, even if they are not necessarily natives of the destination. They facilitate the tourist's experiential process by blending in with the local life that is on display. For example, during village tours some of the Javanese guides wear a traditional conic straw hat that is also worn by the villagers working in the rice fields (attire the guides would never wear when they are not guiding). By doing this, the guides subtly portray themselves

\section{Copyright - 2007 : Tourism Recreation Research Subscribe Online at www.trrworld.org}


as more local than they really are. It is, indeed, necessary to qualify the 'localness' of the guides under study. In Yogyakarta, all but one guide was born and raised within the province (but not necessarily the city). In Arusha, there is more diversity, with guides coming from all over the country and belonging to different ethnic groups. For most guides, a visit to a Javanese desa (village) or Maasai boma (settlement) is as exotic as it is for foreign tourists. Paradoxically, guides rely on global tourism discourses to capitalize on their own background and signal their authenticity as truly 'local'. Their wide knowledge and international experience help them to present the globalized reality around them as distinctively local. However, they will seldom reveal that they themselves have travelled abroad.

While tour guides specialize in reproducing currently popular global discourses about heritage and culture (e.g., focusing on sustainability and everything 'eco'), tourists assume the local authenticity of the guides' narratives and knowledge. Both parties are usually unaware of the classificatory schemes and scripts behind the generalized representations used. This is because it is difficult to trace who the actual producers of tourism discourses are. Guides appropriate imaginaries of their own culture and heritage that are deeply rooted in foreign (mostly Western) ideological representations of 'Otherness'. To be a professional guide is to familiarize oneself with an 'exotic' worldview. Western tourists are unaware of the fact that the actual producers of local tourism discourses come out of their own cultural backyard. For Asian tourists, heritage interpretation by guides seems to be much less important than the mere fact of 'being there' (and having proof of that presence by taking pictures). Probably, this is linked to the fact that, although rapidly growing, the phenomenon of Asian tourists travelling far from their home country is more recent than the more established Western tourism. Even if guides learn to approach tourists from different backgrounds in culturally appropriate ways, the core of their narratives remains equally influenced by globally circulating tourism discourses.

Even if guides are pressured from various interest groups to perform in certain ways, tour guiding can never be fully controlled and tourism discourses are never be completely replicated. On some occasions, the tautology is broken. The original message can be subtly modified and resisted, and the learned scripts might be tempered with unfamiliar elements that are brought out. The guides under study, for example, often prefer to align themselves on the 'us-tourist' side of the 'us-them' binary, by distancing themselves from the locals encountered during a trip. This is achieved through the subtle manipulation of demonstrative and personal pronouns, or temporal and spatial expressions.
Humour is probably the most common device guides draw on to align themselves with tourists. However, since humour is a culturally sensitive mechanism, the magic trick in intercultural interaction only works if there is a shared frame of reference. This requires a substantive amount of learning through trial and error.

Clearly, various schemas of identity and identification are at work while guiding. When talking about the destination as a generalized place, the guides position themselves as locals (respecting the global canon). However, when referring to their own person(ality), they prefer to be aligned alongside the tourists. One possible explanation for this position shift is the fact that during the guide-tourist interaction not only global imaginaries are at play but also the individual imaginaries of the guide. Having close contact with foreigners is considered locally as status enhancing. Many guides see tourists as their gateway into a better world. The privileged interaction with foreigners nourishes their dreams of escape from the harshness of their local life. However, as many aspiring guides realize, the most realistic chance of improving their quality of life is, first, by becoming successful guides. In order to do so, they need to find the right balance in their narratives and practices between their own imaginaries and those of the tourism industry (and, by extension, the tourists). Finally, it is important to acknowledge that not everything that happens during a tour is necessarily under the control of the guides.

\section{Conclusion}

Thinking of globalization and local differentiation as being opposed to each other is not very helpful in understanding and explaining contemporary tourism. The constant (re)shaping of 'the local' is in many respects part of and simultaneously occurring with the globalizing process itself. By carrying out research on the contact zone between the global system of tourism and local tourism destinations, ethnographies of tourism - such as the one outlined in this paper - contribute to 'dynamic tourism studies' (Yamashita 2003). By studying the daily practices of local guides and the way they (re)present and actively (re)construct local culture for a diversified audience of tourists, one can learn a lot about how processes of globalization and localization are intimately intertwined and how this is transforming culture - through tourism and other channels. This study brings to light that the processes of negotiation, regarding the interpretation and presentation of a particular heritage site, are highly complex, multifaceted, and flexible owing to the involvement of various stakeholders in these interactions.

Tour guiding involves a number of supplementary and sometimes conflicting sub-roles, of which guides themselves,

\section{Copyright - 2007 : Tourism Recreation Research Subscribe Online at www.trrworld.org}


in their drive for professional status, emphasize interpretation. This is especially relevant in poor countries such as Indonesia and Tanzania where guides are often the only local interpretative mediation between tourists and sights. By examining how guides in Yogyakarta and Arusha are familiarized with seducing tourism tales through formal and informal training and through the practice of guiding, it becomes evident that global tourism imaginaries are constantly being (re)contextualized. Relying on both discursive and non-verbal practices, guides learn how to present tourists with a commoditized and mystified version of their heritage, represented and packaged as 'local' for global export. Peoples and places around the world are endlessly reinvented as global tourism creates powerful socio-cultural representations of them. 'Seducation' is the author's neologism to denote the learning process of appropriating globally circulating seductive discourses to actively folklorize, ethnicize, and exoticize the local distinctiveness and uniqueness of places like Yogyakarta and Arusha that are constantly being fragmented by outside influences.

Similar activities in which the guides in Indonesia and Tanzania are engaged illustrate the increasing complexity of international tourism and its socio-cultural dynamics. Of course, the author acknowledges that the guides studied are front-runners in their respective contexts. Stimulated by their European employers and their personal travel experiences abroad, they have a clear advantage over other local guides in developing countries who have fewer opportunities to develop their professional skills. However, they do share a similar agency. Although guiding performance is often staged and routinized, the reproduction of the rehearsed narratives is never complete or devoid of deviation. Tourism tales may be the primary engine of myth and culture-in-the-making, but they are neither monolithic nor uncontested. Tourism discourses are not closed or rigid systems, but rather open systems, which are always put at risk by what happens in actual interactions. In other words, heritage interpretation is not fixed, but is the site of constant contestation of meaning. For example, guides do not blindly copy the learned canons but use their agency to strategically position themselves on changing sides of the 'us' versus 'them' continuum that is so prevalent in all tourism imaginaries.

The interaction between guides and guests typifies a socio-cultural moment in which various imaginaries meet, clash, and grapple with each other, often in contexts of highly asymmetrical power relations. Every encounter is unpredictable and a new challenge, even if the guide is well experienced. Normative global templates provide orienting frameworks but are rarely scripts by which life must be lived. Even if both guests and guides are active players in the reproduction of global tourism discourses, there is mediation at every level, and there is always room for alternative or counter-discourses. However, successes and failures are not equally attributed to each. These and other related issues of power, status, and control in tourism discourses and interpretation are obviously of central importance. It is, therefore, imperative to analyse how globalized interpretive discourses can be understood in many ways, and under what social circumstances they are produced and consumed. A productive way of doing this, as outlined in this paper, is by combining sociolinguistic analysis with detailed ethnography to study how the 'culture of tourism' circulates around the globe. Future research will determine the extent to which some of the findings described here can be generalized to other socio-cultural contexts.

\section{Acknowledgements}

An earlier version of this paper was presented at the closing plenary session of the ‘On Voyage: New Directions in Tourism Theory' International Conference, University of California at Berkeley, USA, October 7-8, 2005.

\section{References}

ATELJEVIC, I. (2000). Circuits of Tourism: Stepping Beyond the 'Production/Consumption' Dichotomy. Tourism Geographies 2(4): 369-388. BÆRENHOLDT, J. O., HALDRUP, M., LARSEN, J. and URRY, J. (2004). Performing Tourist Places. Aldershot. Ashgate.

BRAS, K. (2000). Image-Building and Guiding on Lombok: The Social Construction of a Tourist Destination. Amsterdam. ATLAS Publications.

BRUNER, E. M. (2005). Culture on Tour: Ethnographies of Travel. Chicago. University of Chicago Press.

CLIFFORD, J. (1997). Routes: Travel and Translation in the Late Twentieth Century. Cambridge. Harvard University Press.

COLEMAN, S. and CRANG, M. (2002). Tourism: Between Place and Performance. New York. Berghahn Books.

DANN, G. M. S. (1996). The Language of Tourism: A Sociolinguistic Perspective. Wallingford. CABI.

DU GAY, P., HALL, S., JANES, L., MACKAY, H. and NEGUS, K. (1997). Doing Cultural Studies: The Story of the Sony Walkman. London. Sage.

EDENSOR, T. (2001). Performing Tourism, Staging Tourism: (Re)Producing Tourist Space and Practice. Tourist Studies 1(1): 59-81.

FAIRCLOUGH, N. (2003). Analysing Discourse: Textual Analysis for Social Research. London. Routledge.

GAONKAR, D. P. and LEE, B. (2002). New Imaginaries (Theme issue). Public Culture 14(1).

HALL, C. M. and TUCKER, H. (2004). Tourism and Postcolonialism: Contested Discourses, Identities and Representations. London. Routledge.

\section{Copyright - 2007 : Tourism Recreation Research Subscribe Online at www.trrworld.org}


HANNAM, K. and KNOX, D. (2005). Discourse Analysis in Tourism Research: A Critical Perspective. Tourism Recreation Research 30(2): 23-30. JENKINS, O. H. (2003). Photography and Travel Brochures: The Circle of Representation. Tourism Geographies 5(3): 305-328.

JOHNSON, R. (1986). What is Cultural Studies Anyway? Social Text: 1638-80.

MORGAN, N. and PRITCHARD, A. (1998). Tourism Promotion and Power: Creating Images, Creating Identities. Chichester. John Wiley.

MORGAN, N., PRITCHARD, A. and PRIDE, R. (2002). Destination Branding: Creating the Unique Destination Proposition. Oxford. ButterworthHeinemann.

MOSCARDO, G. (1998). Interpretation and Sustainable Tourism: Functions, Examples and Principles. The Journal of Tourism Studies 9(1): 2-13.

MOWFORTH, M. and MUNT, I. (2003). Tourism and Sustainability: Development and New Tourism in the Third World (Second edition). London. Routledge.

NORTON, A. (1996). Experiencing Nature: The Reproduction of Environmental Discourse through Safari Tourism in East Africa. Geoforum 27(3): 355-373.

POND, K. L. (1993). The Professional Guide: Dynamics of Tour Guiding. New York. Van Nostrand Reinhold.

PORTER, B. W. and SALAZAR, N. B. (2005). Heritage Tourism, Conflict, and the Public Interest. International Journal of Heritage Studies 11(5).

PRATT, M. L. (1992). Imperial Eyes: Travel Writing and Transculturation. London. Routledge.

ROJEK, C. and URRY, J. (1997). Touring Cultures: Transformations of Travel and Theory. London. Routledge.

SAID, E. W. (1994). Orientalism (Revised edition). New York. Vintage Books.

SALAZAR, N. B. (2005). Tourism and Glocalization: 'Local' Tour Guiding. Annals of Tourism Research 32(3): 628-646.

SALAZAR, N. B. (2006). Touristifying Tanzania: Global Discourse, Local Guides. Annals of Tourism Research 33(3): 833-852.

SALAZAR, N. B. and PORTER, B. W. (2004). Heritage and Tourism: PIA and Global Interests. Anthropology in Action 11(2/3).

SELWYN, T. (1996). The Tourist Image: Myths and Myth Making in Tourism. Chichester. John Wiley.

SILVERSTEIN, M. and URBAN, G. (1996). Natural Histories of Discourse. Chicago. University of Chicago Press.

TILDEN, F. (1967). Interpreting Our Heritage (Revised edition). Chapel Hill. University of North Carolina Press.

TORGOVNICK, M. (1990). Gone Primitive: Savage Intellects, Modern Lives. Chicago. The University of Chicago Press.

URBAN, G. (2001). Metaculture: How Culture Moves through the World. Minneapolis. University of Minnesota Press.

URRY, J. (2002). The Tourist Gaze (Second edition). London. Sage.

UZZELL, D. (1989). Heritage Interpretation. London. Belhaven Press.

WEILER, B. and HAM, S. (2001). Tour Guides and Interpretation. In Weaver, D. (ed) Encyclopaedia of Ecotourism. Wallingford. CABI.

YAMASHITA, S. (2003). Bali and Beyond: Explorations in the Anthropology of Tourism. New York. Berghahn Books.

Submitted: June 11, 2006

Accepted: November 06, 2006.

\section{Copyright - 2007 : Tourism Recreation Research Subscribe Online at www.trrworld.org}

